\title{
openheart Early coronary angiography and survival after out-of-hospital cardiac arrest: a systematic review and meta- analysis
}

\author{
Rohan Khera, ${ }^{1}$ Sheena CarlLee, ${ }^{2}$ Amy Blevins, ${ }^{3}$ Marin Schweizer, ${ }^{1,4}$ Saket Girotra ${ }^{4,5}$
}

\begin{abstract}
- Additional material is published online only. To view please visit the journal online (http://dx.doi.org/10.1136/ openhrt-2018-000809).
\end{abstract}

To cite: Khera R, CarlLee S, Blevins A, et al. Early coronary angiography and survival after out-of-hospital cardiac arrest: a systematic review and metaanalysis. Open Heart 2018;5:e000809. doi:10.1136/ openhrt-2018-000809

RK and SC contributed equally.

RK and SC are joint first authors.

Received 25 May 2018

Revised 15 August 2018

Accepted 31 August 2018

Check for updates

(c) Author(s) (or their employer(s)) 2018. Re-use permitted under CC BY-NC. No commercial re-use. See rights and permissions. Published by BMJ.

For numbered affiliations see end of article.

Correspondence to Dr Saket Girotra; saket-girotra@ uiowa.edu

\section{ABSTRACT}

Background Although acute myocardial infarction is a common cause of out-of-hospital cardiac arrest (OHCA), the role of early coronary angiography in OHCA remains uncertain. We conducted a meta-analysis of observational studies to determine the association of early coronary angiography with survival in OHCA.

Methods We searched multiple electronic databases for published studies on early coronary angiography in OHCA between 1 January 1990 and 18 January 2017. Studies were included if (1) restricted to only OHCA, (2) included an exposure group that underwent early coronary angiography within 1 day of arrest onset and a concurrent control group that did not undergo early coronary angiography, and (3) reported survival outcomes. We used a random-effects model to obtain pooled OR. $\mathrm{I}^{2}$ statistics and Cochran's $Q$ test were used to determine betweenstudy heterogeneity.

Results A total of 17 studies with 14972 patients were included, of whom 6424 (44\%) received early coronary angiography. Early coronary angiography was associated with higher odds of survival (pooled OR $2.54(95 \% \mathrm{Cl}$ 1.94 to 3.33)) and survival with favourable neurological outcome (pooled OR 2.37 (95\% Cl 1.71 to 3.28)). However, there was substantial heterogeneity in our pooled estimate $\left(l^{2}=88 \%\right.$ and $p$ value for Cochran's test $<0.0001$ for both outcomes). The large heterogeneity in pooled estimates was reduced after including adjusted estimates when available, and was explained by differences in methodological rigour and characteristics of included studies.

Conclusion Among patients resuscitated from OHCA, early coronary angiography is associated with increased survival to discharge and favourable neurological outcome.

\section{INTRODUCTION}

Out-of-hospital cardiac arrest (OHCA) affects nearly 400000 patients each year in the USA and is associated with poor survival. ${ }^{12}$ Acute myocardial infarction (AMI) is a common cause of OHCA especially in patients with ventricular arrhythmias. ${ }^{3}$ While early coronary angiography and revascularisation are the standard of care in $\mathrm{AMI},{ }^{4}$ uncertainty remains regarding the effectiveness of an

\section{Key questions}

What is already known about this subject?

- Acute myocardial infarction is a common cause of out-of-hospital cardiac arrest (OHCA).

- Although early coronary angiography is associated with improved survival outcomes in prior studies of patients with OHCA, there is substantial heterogeneity in the effect.

What does this study add?

- In this updated systematic review and meta-analysis of observational studies, we found that early coronary angiography was associated with nearly twofold higher odds of survival and favourable neurological outcome.

- Large heterogeneity in the effect estimate was explained in part by differences in methodological rigour and included patient characteristics.

How might this impact on clinical practice?

- Early coronary angiography is associated with improved odds of survival and favourable neurological outcome in OHCA.

- In the absence of randomised controlled trials, our findings support current guidelines that recommend use of early coronary angiography as a means to improve survival in OHCA.

early invasive strategy in patients with OHCA, particularly in patients without obvious signs of ischaemia on an ECG. This issue is of critical importance since a 12-lead ECG has been shown to be unreliable in diagnosing AMI in resuscitated patients. ${ }^{3}$ While a routine early invasive strategy in postarrest patients may be beneficial in restoring myocardial perfusion in such patients, its benefit may be counterbalanced with the risk of invasive procedures in patients in whom prognosis for neurological recovery may be unclear.

In the absence of data from randomised controlled trials, the evidence supporting a benefit of early coronary angiography in OHCA comes entirely from observational 
studies. ${ }^{5-7}$ Although most of these studies have shown early coronary angiography to be associated with improved survival, the magnitude of effect varies across studies. Likewise, previous meta-analyses have found early coronary angiography to be associated with survival in patients with OHCA. ${ }^{89}$ However, substantial heterogeneity was noted in the pooled survival estimate, which was not adequately explored. Moreover, the meta-analysis was further limited by inclusion of studies of patients with in-hospital cardiac arrest (IHCA) ${ }^{10}$ Finally, since the publication of the previous meta-analyses, several large studies that collectively enrolled $>8000$ patients and were methodologically rigorous have since been published. ${ }^{67}$

Therefore, our overarching objective was to conduct an updated systematic review and meta-analysis of observational studies that compared the use of early coronary angiography, defined as coronary angiography within 24 hours from the onset of cardiac arrest, and survival and neurological outcome in patients following successful resuscitation from OHCA, and determine the sources of heterogeneity in effect estimates observed in prior studies. Our hypothesis was that early coronary angiography would be associated with improved survival and neurological outcome in patients with OHCA. In addition, we hypothesised that heterogeneity in survival estimates noted in previous meta-analyses would be explained by differences in methodological rigour and patient characteristics of included studies.

\section{METHODS}

The study was conducted according to the Preferred Reporting Items for Systematic Reviews and Meta-Analyses guidelines and the Meta-analysis of Observational Studies in Epidemiology checklist (online supplementary table 1). ${ }^{11} 12$ An experienced health sciences librarian ran extensive literature searches in MEDLINE via Ovid, Cochrane Database of Systematic Reviews, Database of Abstracts of Reviews of Effects, Cochrane Central Register of Controlled Trials, Embase, Web of Science, and ClinicalTrials.gov between 1 January 1990 and 18 January 2017. We restricted our search to studies published after 1990, since coronary angiography and percutaneous revascularisation had not been incorporated into clinical care for emergent conditions like AMI until that period. Search terms included subject headings and keywords for cardiac arrest, asystole, sudden cardiac death, coronary angiography, cardiac catheterisation, coronary angioplasty and percutaneous coronary intervention (PCI). No filters for language were applied to the searches. Full search strategies from all databases are listed in the (online supplementary appendix). We also reviewed the references from all included articles to identify additional studies that were not identified in the initial search.

\section{Study selection}

To be included in the meta-analysis, studies were required to meet the following inclusion criteria: (1) restricted to patients with OHCA in studies and excluded patients with IHCA, (2) included an exposure group that underwent early coronary angiography within 24 hours of cardiac arrest, (3) included a concurrent control group that did not undergo early coronary angiography (may undergo coronary angiography 24 hours after OHCA or not undergo coronary angiography at all), and (4) reported at least one of the following as an outcome: in-hospital survival, 30-day survival or in-hospital survival with favourable neurological outcome. We excluded studies that were case reports, review articles, commentaries, guidelines, studies that combined both IHCA and OHCA, studies that did not identify patients undergoing early coronary angiography separately from patients undergoing coronary angiography at any point during the hospital course, studies that did not include a concurrent control group (eg, historical control), and studies that compared outcomes in patients according to receipt of PCI rather than early coronary angiography (figure 1).

\section{Outcomes}

The primary outcome of interest was in-hospital survival. The secondary outcome was survival with favourable neurological outcome. The Cerebral Performance Category (CPC) score is the tool most commonly used to assess neurological outcome at discharge. A CPC score of 1 denotes mild or no neurological disability, 2 moderate neurological disability, 3 severe neurological disability, 4 coma or vegetative state, and 5 brain death. Survival with a CPC score of 1 or 2 is commonly used to denote survival with favourable neurological outcome. In studies where neurological assessment was performed with a modified Rankin Scale, we used that study's definition of survival with favourable neurological outcome, since there is proven correlation between 'good outcome' on these two scales.

\section{Data extraction and quality assessment}

Two reviewers (SC and RK) evaluated each study for inclusion and independently extracted the data into a data abstraction form. A third independent reviewer (SG) evaluated the data abstraction forms prepared by the two reviewers and assessed agreement between them. All inconsistencies were resolved with consensus. The two independent reviewers abstracted data on publication year, study design, data collection (prospective or retrospective), timing of early coronary angiography $(<6$ hours, $<24$ hours and so on), patient population (eg, mean age, proportion of patients with shockable rhythms, ST-elevation myocardial infarction (STEMI), receiving early coronary angiography and PCI, receiving concomitant therapeutic hypothermia), outcome assessed (in-hospital survival, survival with favourable neurological outcome), definition of study outcome (eg, CPC score or modified Rankin Scale for neurological assessment), and the number of patients in each exposure group that experienced a study outcome. In addition, data on the adjusted OR and 95\% CI between early coronary angiography and survival outcome from studies that reported such data were also extracted. 


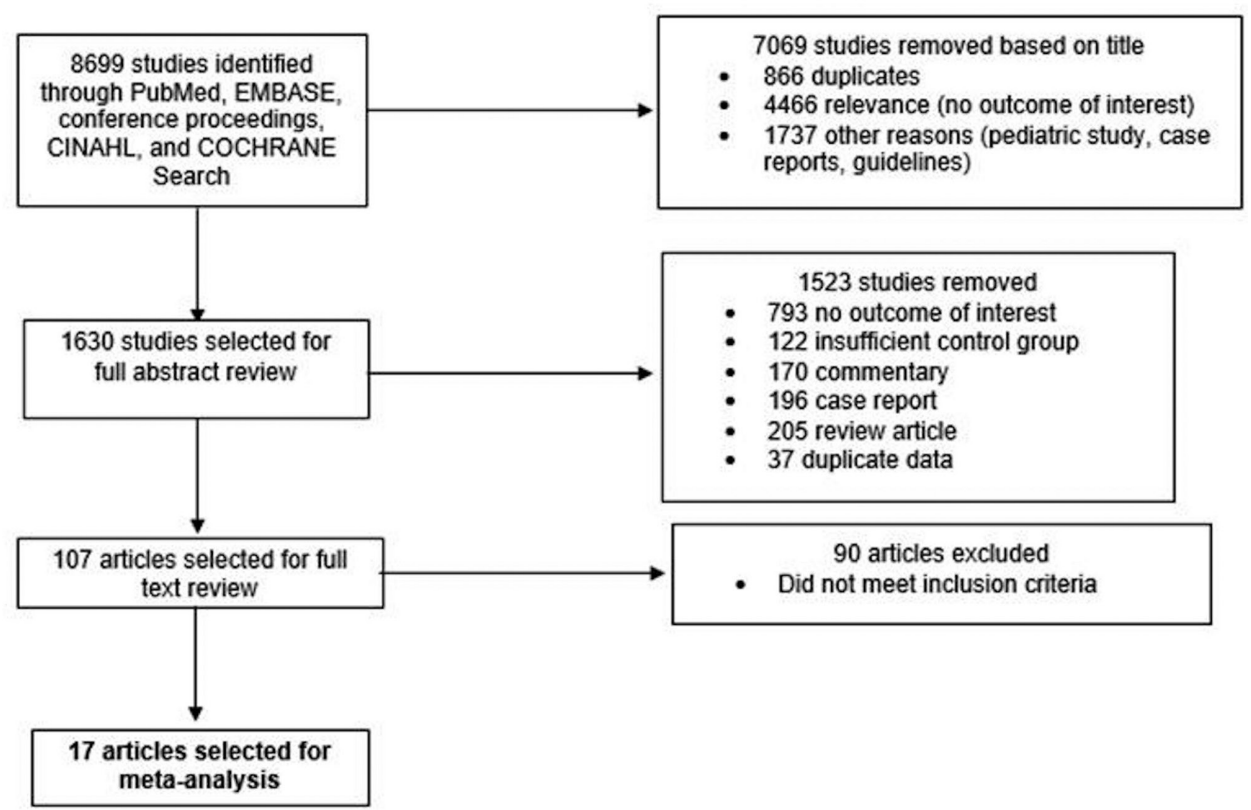

Figure 1 Preferred Reporting Items for Systematic Reviews and Meta-Analyses (PRISMA) diagram. CINAHL, Cumulative Index to Nursing and Allied Health Literature.

Study quality was assessed using the Newcastle-Ottawa Scale, a tool that is widely used for assessing the quality of non-randomised studies included in a meta-analysis. ${ }^{13}$ The tool evaluates each study on eight items, which are categorised into three groups-selection of the study groups, comparability of the groups, and ascertainment of either the exposure or the outcome within each group.

\section{Statistical analysis}

We used the extracted raw data to calculate the natural logarithm of the OR and its variance, and used these estimates for pooling effects in all studies. We used a random-effects model with inverse variance weighting to generate a pooled OR of the effect estimate. ${ }^{14}$ Results for individual studies and summary results are expressed as an OR with 95\% CI. Some studies reported the effect of early coronary angiography on study outcomes after adjusting for potential confounders. We conducted additional analyses in which we used the adjusted OR and its variance from such studies, and raw unadjusted data if no adjusted results were provided, to calculate a pooled estimate using the generic inverse variance method. Heterogeneity was assessed using the Cochran's $Q$ statistic, which is based on a $\chi^{2}$ test with $\mathrm{k}-1 \mathrm{df}$ (where $\mathrm{k}$ is the number of studies).${ }^{15}$ Given the low power of the test of heterogeneity, we also calculated the $\mathrm{I}^{2}$ statistic, which quantifies the proportion of between-study variation that is due to heterogeneity. Heterogeneity was considered to be substantial if the $\mathrm{I}^{2}$ value was $>50 \%$. To determine the extent to which our pooled estimate was influenced by the inclusion of adjusted OR from studies that provided them, we repeated the above analyses after including only the unadjusted OR from all studies to calculate the pooled
OR for survival and survival with favourable neurological outcome, respectively.

We created a funnel plot to visually assess publication bias. All statistical calculations were performed using RevMan V.5.3 (Copenhagen: The Nordic Cochrane Centre, The Cochrane Collaboration, 2014) and STATA V.14.

\section{Subgroup analyses}

To explore heterogeneity in our estimate, we further examined the association between early coronary angiography and our study outcomes within the following subgroups based on methodological rigour and patient characteristics. Studies were defined as methodologically rigorous if methods to account for confounding due to indication (eg, propensity score analysis, multivariable logistic regression and so on) and appropriate confounding variables were included and information regarding model performance (eg, calibration, discrimination) was provided. Given that the relative impact of early coronary angiography may differ according to initial rhythm (eg, ventricular fibrillation) and underlying cause (eg, STEMI), we repeated the above analyses within subgroups defined by initial rhythm (studies of only patients with shockable rhythm vs studies that included all patients) and inclusion or exclusion of patients with STEMI.

\section{RESULTS}

\section{Study characteristics}

The search and review process is summarised in figure 1 . Of the 8699 articles in our initial search, 8592 articles were excluded based on the review of title, or title and abstract. A total of 107 articles were selected for full review, of which 17 articles met our study criteria and were included in the meta-analysis. ${ }^{5-7}$ 16-29 


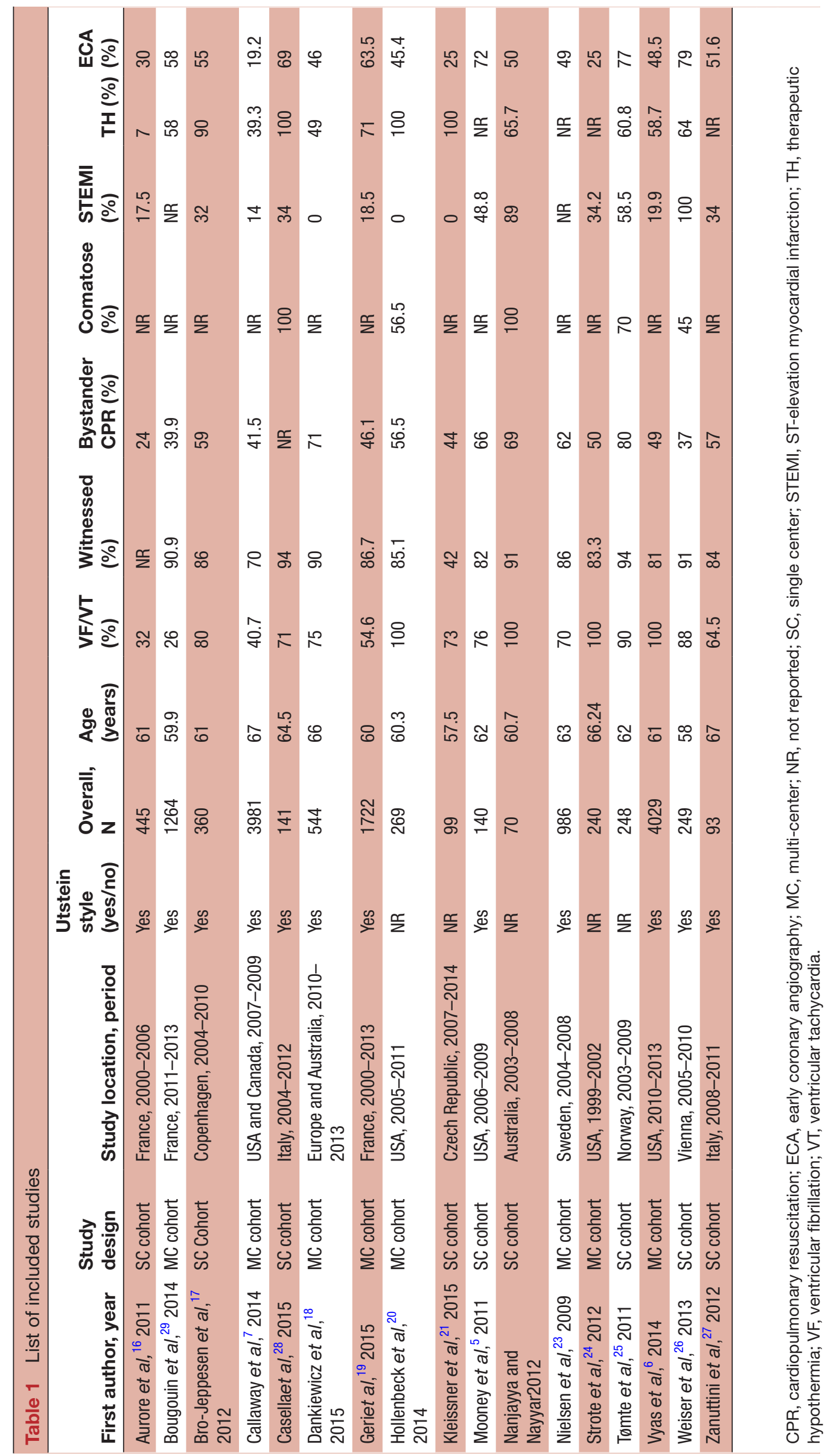


Table 1 provides details of the 17 included studies, which contributed a total of 14792 patients. There were $6424(44 \%)$ patients in the early coronary angiography group and $8368(66 \%)$ patients in the group that did not undergo early coronary angiography. The mean age ranged from 57 to 67 years, with a median age of 62 years. All included studies were cohort studies. Nine of the 17 included studies were single-centre. ${ }^{5} 16172122$ 25-28 Among the included studies, the median proportion of patients with an initial shockable rhythm was $75 \%$ (range: $26 \%-100 \%$ ). Four studies $(23.5 \%)$ were limited to patients with an initial shockable rhythm, ${ }^{62022} 24$ while the remaining included patients with both shockable and non-shockable cardiac arrests. The median rate of STEMI was $32 \%$, ranging from $0 \%$ to $100 \%$, with three studies $(17.6 \%)$ conducted exclusively in patients without STEMI on their presenting ECG. ${ }^{1820} 21$ Only four studies used methods that adequately adjusted for important confounders with the use of either a propensity score analysis or multivariable logistic regression, ${ }^{6} 72026$ three reported risk-adjusted estimates for our primary outcome of overall survival, ${ }^{6720}$ and three for our secondary outcome of favourable neurological survival. ${ }^{6726}$

\section{Survival outcomes}

Of the 17 studies included in this analysis, 16 (94\%)

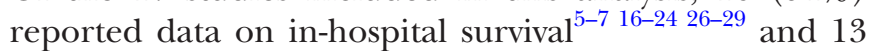
$(76 \%)$ reported data on survival with favourable neurological outcome..$^{5-7} 1718$ 20-28 In pooled analysis, we found a significant positive association between the use of early coronary angiography and survival to discharge (OR 2.54 (95\% CI 1.94 to 3.33)). Likewise, early coronary angiography was also associated with favourable neurological outcome (OR 2.37 (95\% CI 1.71 to 3.28)). However, there was significant heterogeneity in the effect estimate across studies $\left(\mathrm{I}^{2}=88 \%\right.$ for both outcomes, $\mathrm{p}$ value for

\begin{tabular}{|c|c|c|c|c|c|c|c|c|}
\hline Study or Subgroup & \multicolumn{2}{|c|}{ Early Cath } & \multicolumn{2}{|c|}{ No Early Cath } & Weight & $\begin{array}{c}\text { Odds Ratio } \\
\mathrm{M}-\mathrm{H} \text {, Random, } 95 \% \mathrm{Cl}\end{array}$ & \multicolumn{2}{|c|}{$\begin{array}{c}\text { Odds Ratio } \\
\text { M-H, Random, } 95 \% \mathrm{CI}\end{array}$} \\
\hline Aurore & 30 & 133 & 30 & 312 & $6.3 \%$ & $2.74[1.57,4.76]$ & & 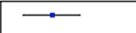 \\
\hline Bougouin & 244 & 733 & 38 & 531 & $7.4 \%$ & $6.47[4.50,9.32]$ & & $\rightarrow$ \\
\hline Bro-Jeppesen & 128 & 198 & 83 & 162 & $7.0 \%$ & $1.74[1.14,2.66]$ & & $\rightarrow$ \\
\hline Callaway & 495 & 765 & 868 & 3216 & $8.2 \%$ & $4.96[4.19,5.86]$ & & $\rightarrow$ \\
\hline Casella & 64 & 97 & 22 & 44 & $5.3 \%$ & $1.94[0.94,4.00]$ & & \\
\hline Dankiewicz & 130 & 252 & 133 & 292 & $7.5 \%$ & $1.27[0.91,1.79]$ & & $\rightarrow$ \\
\hline Geri & 419 & 1094 & 129 & 628 & $8.0 \%$ & $2.40[1.91,3.02]$ & & $\rightarrow$ \\
\hline Hollenbeck & 80 & 122 & 71 & 147 & $6.6 \%$ & $2.04[1.24,3.34]$ & & $\longrightarrow$ \\
\hline Kleissner & 23 & 25 & 64 & 74 & $2.1 \%$ & $1.80[0.37,8.82]$ & & \\
\hline Mooney & 63 & 101 & 15 & 39 & $5.1 \%$ & $2.65[1.24,5.67]$ & & - \\
\hline Nanjaya & 18 & 35 & 12 & 35 & $4.1 \%$ & $2.03[0.78,5.31]$ & & \\
\hline Nielsen & 303 & 479 & 253 & 507 & $7.9 \%$ & $1.73[1.34,2.23]$ & & $\rightarrow$ \\
\hline Strote & 44 & 61 & 87 & 179 & $5.8 \%$ & $2.74[1.46,5.15]$ & & $\longrightarrow$ \\
\hline Vyas & 1484 & 1953 & 1234 & 2076 & $8.3 \%$ & $2.16[1.88,2.47]$ & & - \\
\hline wieiser & 143 & 183 & 18 & 52 & $5.6 \%$ & $6.75[3.45,13.20]$ & & \\
\hline Zanuttini & 29 & 48 & 21 & 45 & $4.7 \%$ & $1.74[0.77,3.97]$ & & - \\
\hline Total $(95 \% \mathrm{CI})$ & & 6279 & & 8339 & $100.0 \%$ & $2.54[1.94,3.33]$ & & \\
\hline Total events & 3697 & & 3078 & & & & & \\
\hline $\begin{array}{l}\text { Heterogeneity. Tau }{ }^{2} \\
\text { Test for overall effect }\end{array}$ & $\begin{array}{l}0.22 ; \mathrm{Ch} \\
z=6.77\end{array}$ & $\begin{array}{l}i^{2}=12 \\
(P<0\end{array}$ & $\begin{array}{l}9.88, \mathrm{df} \\
.000011\end{array}$ & 5 & $<0.00$ & $=88 \%$ & $\begin{array}{c}1 \\
0.1 \\
\text { Favours delay }\end{array}$ & 1 Favours ECA \\
\hline
\end{tabular}

B

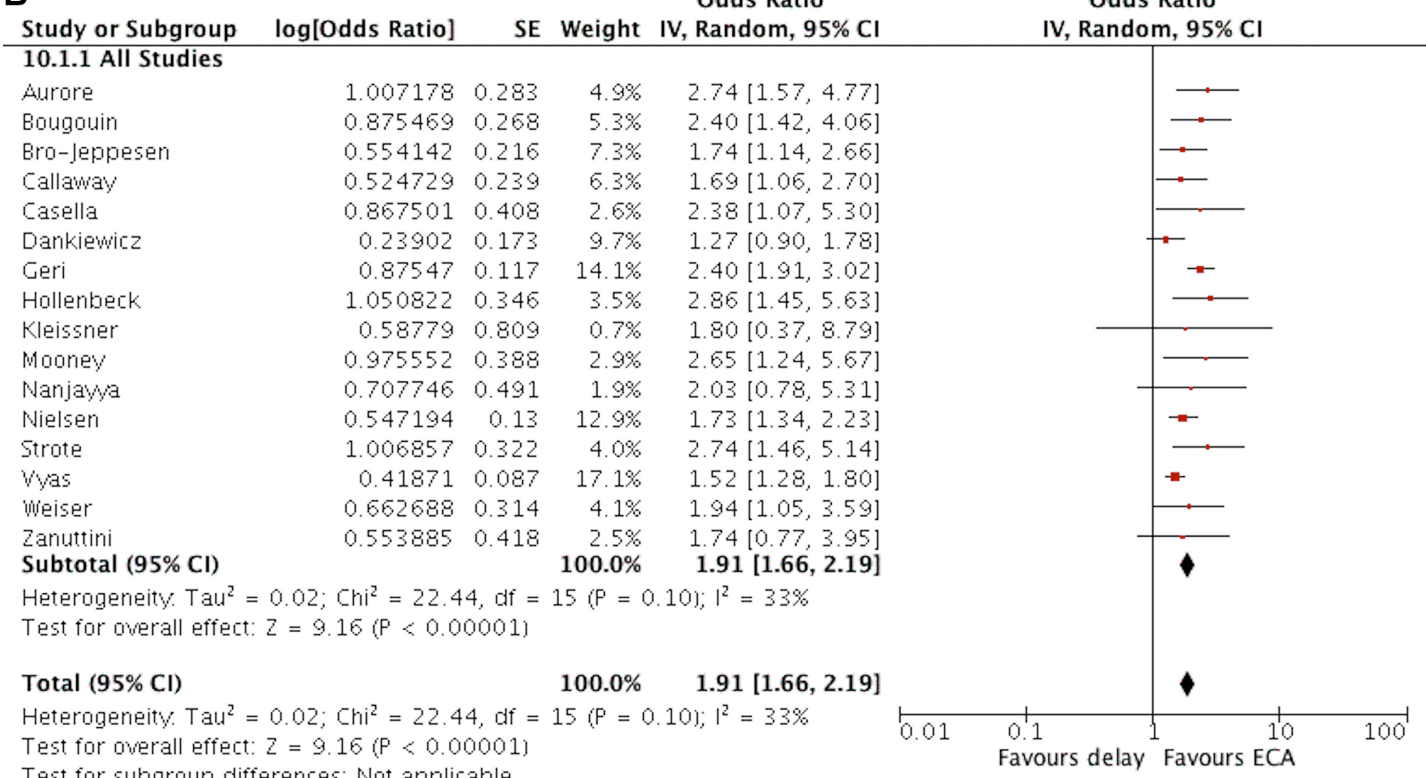

Figure 2 Forest plot of the association between early coronary angiography and survival in patients with out-of-hospital cardiac arrest $A$ : including unadjusted data from all studies. B: including adjusted data when available. cath, catheterisation; ECA, early coronary angiography; IV, inverse variance; M-H, Maentel Haensel. 
Cochran's $Q$ test $<0.0001$, figures $2 A$ and $3 A$ ). In analyses which included adjusted OR from studies that used statistical methods for control of confounding, the effect of early coronary angiography remained significant, but the magnitude of the effect was decreased (survival: OR 1.91 (95\% CI 1.66 to 2.19); favourable neurological outcome: OR 1.93 (95\% CI 1.52 to 2.46$)$ ), and the statistical heterogeneity was reduced $\left(\mathrm{I}^{2}=33 \%\right.$ and $63 \%$, respectively, figures $2 \mathrm{~B}$ and $3 \mathrm{~B}$.

\section{Subgroup analyses}

We conducted additional subgroup analyses to explore heterogeneity in our pool ed estimates, which are summarised in table 2 and online supplementary figures 1-6. There were four studies that were considered methodologically rigorous and reported on in-hospital survival (table 2). In such studies, the pooled OR for the association between early coronary angiography and survival was 1.56 (95\% CI 1.29 to 1.89 ) compared with 2.13 (95\% CI 1.86 to 2.43) from studies which were considered as less rigorous (table 2 and online supplementary figure 1 ). Similar findings were also noted for favourable neurological survival (table 2 and online supplementary figure 2).
In studies which only included patients with an initial shockable rhythm (4 out of 17 studies), early coronary angiography was associated with a twofold increase in odds of survival to discharge (OR 2.03 (95\% CI 1.38 to 2.99); table 2 and online supplementary figure 3 ) and a $50 \%$ increase in odds of favourable neurological survival (OR 1.50 (95\% CI 1.29 to 1.73); table 2 and online supplementary figure 4). Heterogeneity in the effect estimates was higher for survival $\left(\mathrm{I}^{2}=51 \%\right.$ vs $\left.20 \%\right)$ but lower for favourable neurological survival $\left(\mathrm{I}^{2}=0 \%\right.$ vs $\left.61 \%\right)$ in studies that only included patients with shockable rhythm, compared with studies which included patients regardless of the initial rhythm. Studies stratified by the inclusion of patients with STEMI are reported in table 2 and online supplementary figures 5,6 ). In general, the association between early coronary angiography and survival outcomes was consistent with our overall findings.

Table 3 summarises the risk of bias as assessed using the Newcastle-Ottawa Scale. In general, most of the included studies were of moderate quality. The median quality score was 7, and only three studies had a score of 9 on the Newcastle-Ottawa Scale.

\begin{tabular}{|c|c|c|c|c|c|c|c|c|c|}
\hline \multirow{2}{*}{$\mathrm{A}_{\text {Study or Subgroup }}$} & \multicolumn{2}{|c|}{ Early Cath } & \multicolumn{2}{|c|}{ No Early Cath } & Weight & $\begin{array}{c}\text { Odds Ratio } \\
\text { M-H, Random, } 95 \% \mathrm{Cl}\end{array}$ & \multicolumn{3}{|c|}{$\begin{array}{c}\text { Odds Ratio } \\
\mathrm{M}-\mathrm{H}, \text { Random, } 95 \% \mathrm{Cl}\end{array}$} \\
\hline & 127 & 130 & 80 & 89 & $3.9 \%$ & $4.76[1.25,18.12]$ & & & 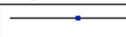 \\
\hline Callaway & 413 & 765 & 579 & 3216 & $10.8 \%$ & $5.34[4.52,6.32]$ & & & - \\
\hline Casella & 53 & 97 & 8 & 44 & $6.3 \%$ & $5.42[2.28,12.86]$ & & & \\
\hline Dankiewicz & 122 & 251 & 119 & 290 & $10.0 \%$ & $1.36[0.97,1.91]$ & & & 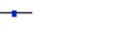 \\
\hline Hollenbeck & 74 & 122 & 65 & 147 & $8.9 \%$ & $1.94[1.19,3.17]$ & & & $\longrightarrow$ \\
\hline Kleissner & 15 & 25 & 40 & 74 & $5.9 \%$ & $1.27[0.51,3.20]$ & & & \\
\hline Mooney & 60 & 101 & 12 & 39 & $6.8 \%$ & $3.29[1.50,7.24]$ & & & \\
\hline Nanjaya & 14 & 35 & 11 & 35 & $5.5 \%$ & $1.45[0.54,3.89]$ & & & \\
\hline Nielsen & 278 & 479 & 171 & 507 & $10.4 \%$ & $2.72[2.10,3.52]$ & & & $\rightarrow$ \\
\hline Strote & 34 & 43 & 66 & 86 & $6.1 \%$ & $1.14[0.47,2.78]$ & & & \\
\hline Tomte & 76 & 145 & 9 & 29 & $6.3 \%$ & $2.45[1.04,5.74]$ & & & \\
\hline Wyas & 1147 & 1953 & 821 & 2076 & $11.0 \%$ & $2.18[1.92,2.47]$ & & & - \\
\hline weiser & 123 & 197 & 24 & 52 & $8.0 \%$ & $1.94[1.05,3.59]$ & & & - \\
\hline Total $(95 \% \mathrm{CI})$ & & 4343 & & 6684 & $100.0 \%$ & $2.37[1.71,3.28]$ & & & \\
\hline Total events & 2536 & & 2005 & & & & & & \\
\hline $\begin{array}{l}\text { Heterogeneity } \mathrm{Tau}^{2}= \\
\text { Test for overall effect: }\end{array}$ & $\begin{array}{l}0.25 ; \mathrm{Ch} \\
z=5.17\end{array}$ & $\begin{array}{l}\mathrm{i}^{2}=10 \\
(\mathrm{P}<0\end{array}$ & $\begin{array}{l}14.30, \mathrm{df}= \\
.00001 \mathrm{j}\end{array}$ & 12 & $<0.00$ & $11 ; r^{2}=88 \%$ & 0.01 & $\begin{array}{l}0.1 \\
\text { Favours delay }\end{array}$ & Favours EC \\
\hline
\end{tabular}

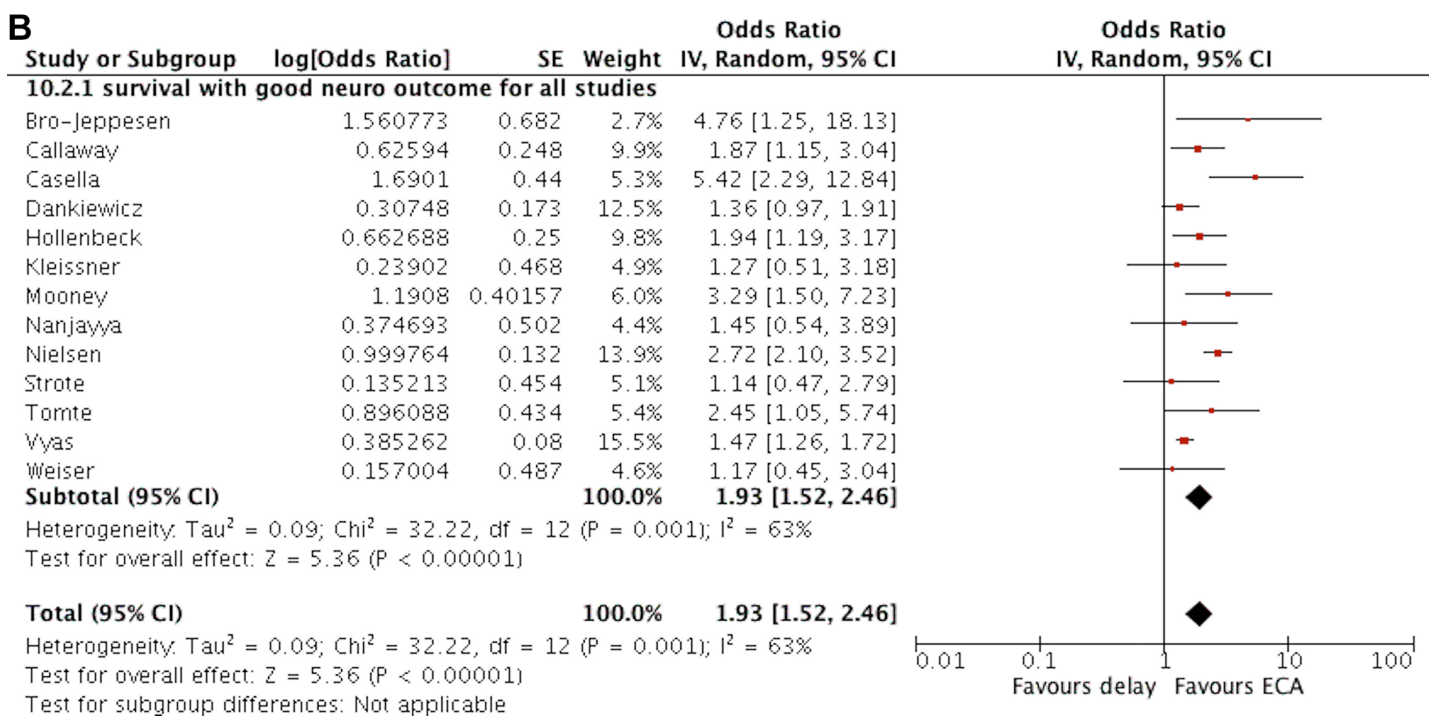

Figure 3 Forest plot of the association between early coronary angiography and survival with favorable neurologic outcome in patients with out-of-hospital cardiac arrest A: including unadjusted data from all studies; B: including adjusted data when available. ECA, early coronary angiography. 


\begin{tabular}{|c|c|c|c|c|}
\hline \multirow[b]{2}{*}{ Subgroups } & \multicolumn{2}{|c|}{ In-hospital survival } & \multicolumn{2}{|c|}{$\begin{array}{l}\text { Survival with favourable } \\
\text { neurological outcome }\end{array}$} \\
\hline & $\begin{array}{l}\text { Pooled OR } \\
(95 \% \mathrm{Cl})\end{array}$ & $I^{2}(\%)$ & $\begin{array}{l}\text { Pooled OR } \\
(95 \% \mathrm{Cl})\end{array}$ & $I^{2}(\%)$ \\
\hline \multicolumn{5}{|l|}{ Methodological rigour } \\
\hline High & $\begin{array}{l}1.56 \\
(1.29 \text { to } 1.89) n=4\end{array}$ & 28 & $\begin{array}{l}1.50 \\
(1.30 \text { to } 1.75) n=2\end{array}$ & 0 \\
\hline \multicolumn{5}{|l|}{ Rhythm } \\
\hline Only included patients with a shockable rhythm & $\begin{array}{l}2.03 \\
(1.38 \text { to } 2.99) n=4\end{array}$ & 51 & $\begin{array}{l}1.50 \\
(1.29 \text { to } 1.73) n=4\end{array}$ & 0 \\
\hline $\begin{array}{l}\text { Included patients with both shockable and non-shockable } \\
\text { rhythm }\end{array}$ & $\begin{array}{l}1.93 \\
(1.66 \text { to } 2.24) n=12\end{array}$ & 79 & $\begin{array}{l}2.20 \\
(1.59 \text { to } 3.05) n=9\end{array}$ & 61 \\
\hline Included patients regardless of whether STEMI was present & $\begin{array}{l}1.91 \\
(1.70 \text { to } 2.23) n=13\end{array}$ & 26 & $\begin{array}{l}2.13 \\
\text { (155 to 2.91) } n=10\end{array}$ & 69 \\
\hline
\end{tabular}

STEMI, ST-elevation myocardial infarction.

\section{Publication bias}

A funnel plot was created to assess publication bias (figure 4). The funnel plot was visually symmetrical, suggesting that the wide search criteria yielded a thorough evaluation of the available evidence.

\section{DISCUSSION}

In this updated meta-analysis, we found that the use of early coronary angiography was associated with higher odds of survival to discharge and favourable neurological survival in patients successfully resuscitated from an OHCA. The observed heterogeneity in pooled estimates was explained, in part, by differences in patient characteristics and methodological rigour of included studies. The overall association of early coronary angiography with improved survival in OHCA was consistent in studies which explicitly accounted for selection bias. However, given the potential for unmeasured confounding variables in observational studies, data from randomised clinical trials would be informative.

Previous meta-analyses have also shown early coronary angiography to be associated with survival. ${ }^{89}$ However, we build on these prior findings in a number of important ways. First, prior meta-analyses were conducted before the recent publication of the two largest studies ${ }^{67}$ which included 3981 and 4029 patients, respectively. Prior to the publication of these two studies, the largest study that examined the use of early coronary angiography in OHCA included less than 1000 patients. ${ }^{23}$ Due to limited sample size, most studies included in the previous meta-analysis only reported unadjusted outcomes as they lacked the statistical power needed to account for selection bias. Given that patients more likely to survive may be more likely to undergo coronary angiography, it is conceivable that the benefit of early coronary angiography was overestimated in such studies. This may explain why the pooled OR of 1.91 in our study, which included adjusted outcomes when available, is lower in our meta-analysis than reported in the previous meta-analyses (OR 2.77 and 2.78). ${ }^{89}$ Second, unlike previous meta-analyses which also included studies that examined use of early coronary angiography in patients with IHCA, ${ }^{10}$ we only focused on patients with OHCA. This is important because the aetiology, response time and survival rate for IHCA are markedly different compared with patients with OHCA, which may bias the association of early coronary angiography with survival in studies that include patients with IHCA and OHCA. Finally, the large heterogeneity in previous meta-analyses limited the interpretability of the pooled estimate from prior studies. Although statistical heterogeneity was still present in our analysis, we found that the heterogeneity in the effect estimates was driven at least in part by differences in methodological rigour and included patient characteristics.

Most of the included studies only reported unadjusted association between early coronary angiography and survival outcomes, which are likely to be confounded by differences between patients who did and did not undergo early coronary angiography. Among studies that were judged as methodologically rigorous, the association of early coronary angiography with study outcomes was more conservative and less heterogeneous in such studies. Given that early coronary angiography is more likely to be offered to patients who may be more likely to survive (such as patients with intact neurological function at the time of admission), failure to account for 


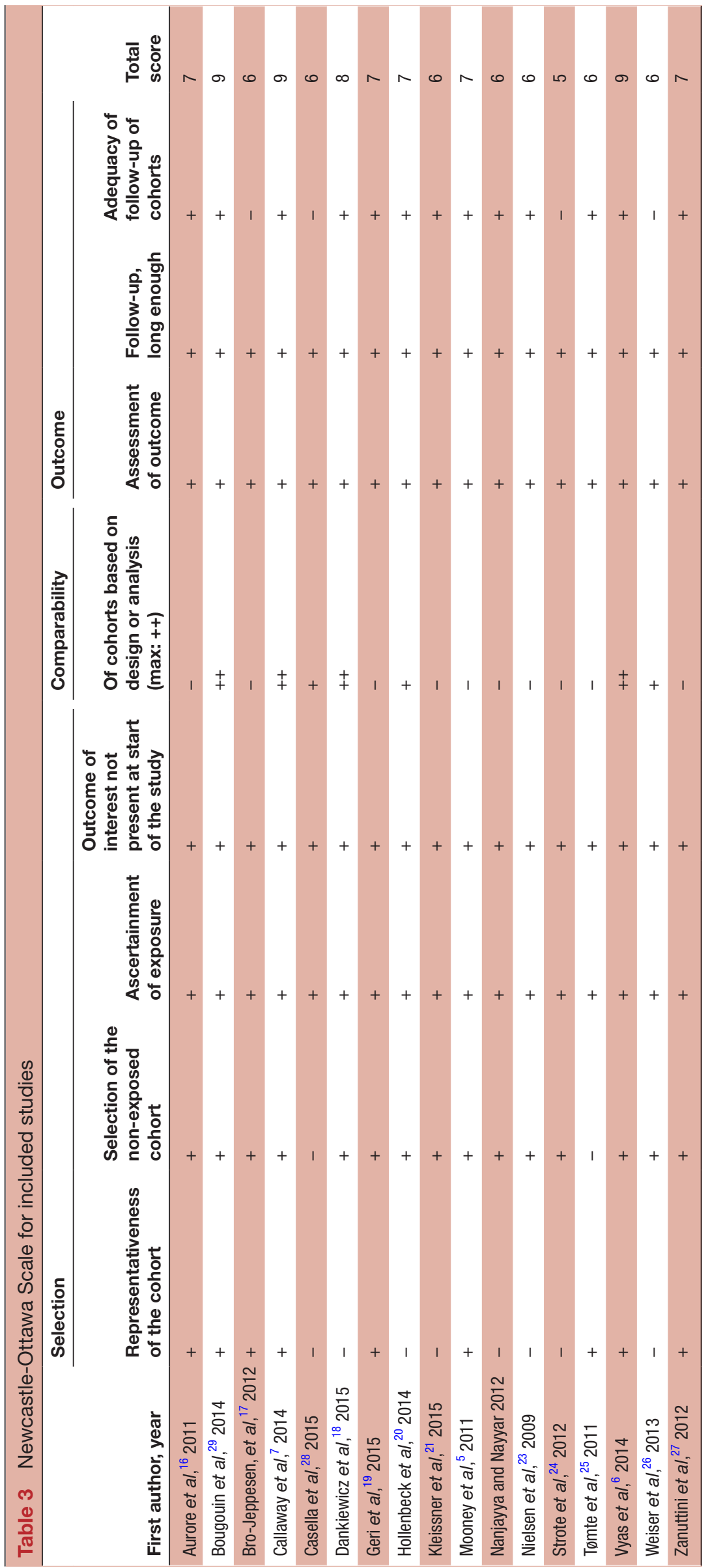




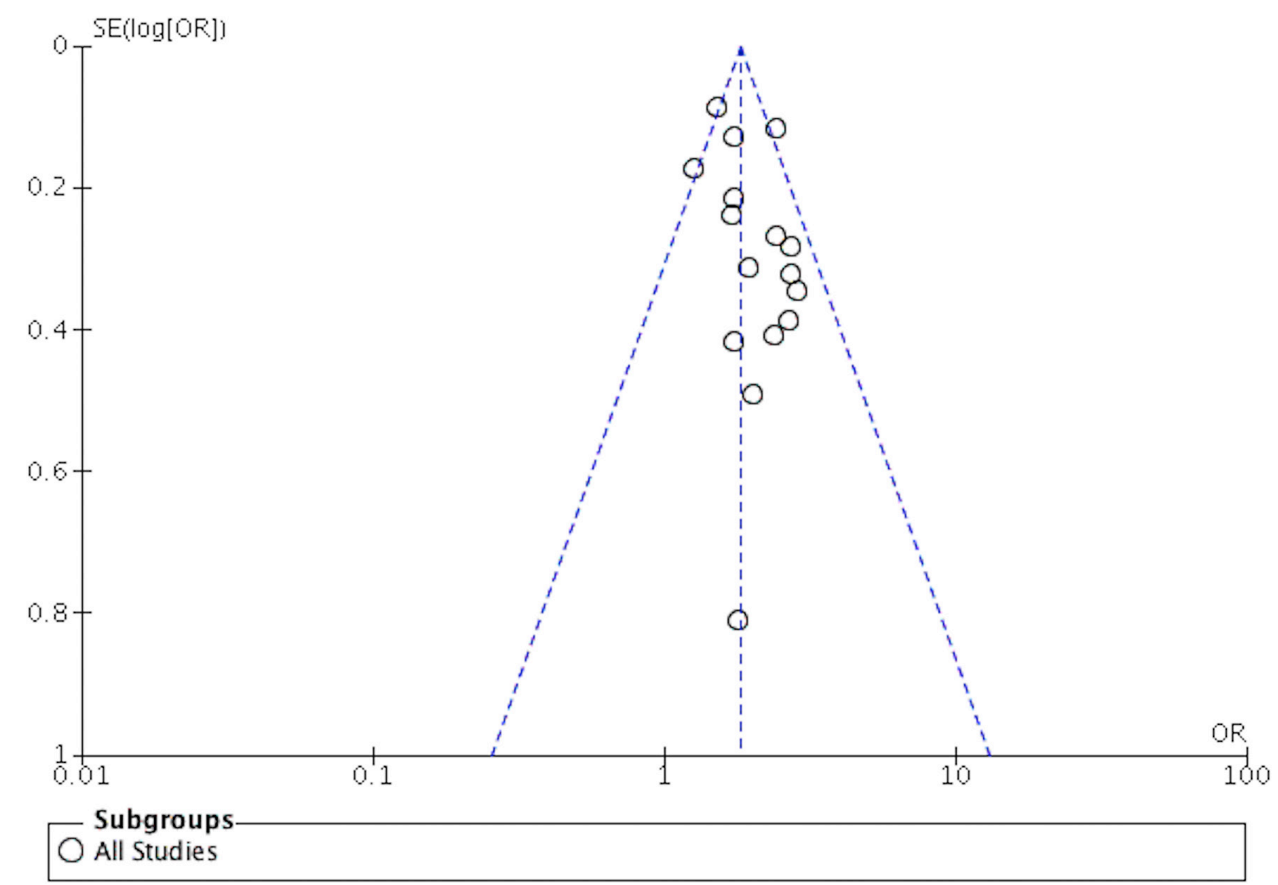

Figure 4 Funnel Plot to assess publication bias

confounding due to indication (or treatment selection bias) in study design may have a significant impact on the validity of observational studies.

We also found that between-study heterogeneity was also explained by differences in patient characteristics of included studies. In particular, survival estimates from studies that only included patients with an initial shockable rhythm were less heterogeneous compared with studies that included all rhythms with regard to favourable neurological outcome. It is likely that patients with OHCA due to an initial shockable rhythm such as ventricular fibrillation are more likely to have AMI as the underlying aetiology of arrest, where the benefit of early coronary angiography is better defined compared with studies that included a more heterogeneous population with regard to initial rhythm. Likewise, differences in studies with regard to proportion of patients with STEMI may have modified the association between early coronary angiography and survival and therefore also explained some of the between-study heterogeneity in the pooled estimates. Future studies would need to determine whether the beneficial effect of early coronary angiography depends on the initial rhythm or the underlying aetiology of cardiac arrest.

Current guidelines recommend early coronary angiography in patients with OHCA especially when an obvious non-cardiac cause is not present. The above benefit is possibly mediated by early PCI. ${ }^{30}$ Although our findings support the above recommendations, several randomised controlled trials are currently ongoing that would provide further evidence regarding the benefit of early coronary angiography in patients resuscitated from OHCA.

Our study findings should be interpreted in light of the following limitations. First, only four of the studies included in our meta-analysis were considered methodologically rigorous. Most studies only reported unadjusted association of early coronary angiography with survival and therefore potential for confounding remains. Second, although we included two large studies that were recently published and were methodologically more rigorous, half of the studies included in this meta-analysis were single-centre, retrospective, enrolled a few hundred patients and were generally of lower quality. Third, the pooled estimate from this meta-analysis needs to be interpreted in the context of statistical heterogeneity among included studies. To address this limitation, we included adjusted estimates when available and conducted stratified analyses and found that at least some of the heterogeneity between included studies was due to differences in methodological rigour and characteristics of included patients. Finally, although we found no evidence of publication bias using the funnel plot, it is still possible that studies that did not show a benefit of early coronary angiography may not have been published.

In conclusion, early coronary angiography is associated with survival to hospital discharge and favourable neurological survival in patients resuscitated from OHCA. In the absence of data from randomised controlled trials, our findings support clinical practice guidelines that recommend use of early coronary angiography as a means to improve survival in OHCA.

\section{Author affiliations}

${ }^{1}$ Division of Cardiology, University of Texas Southwestern Medical Center, Dallas, Texas, USA

${ }^{2}$ Department of Internal Medicine, University of lowa Carver College of Medicine, lowa City, lowa, USA

${ }^{3}$ Ruth Lilly Medical Library, University of Indiana, Indiana University School of Medicine, Indianapolis, Indiana, USA 
${ }^{4}$ Comprehensive Access and Delivery Research and Evaluation (CADRE), lowa City Veterans Affairs Medical Center, lowa City, lowa, USA

${ }^{5}$ Division of Cardiology, Department of Internal Medicine, University of lowa Carver College of Medicine, lowa City, lowa, USA

Funding This study is supported by the National Heart, Lung, and Blood Institute of the National Institutes of Health under awards K08HL122527 (SG). RK received support from the National Heart, Lung, and Blood Institute (5T32HL125247 - 02) and the National Center for Advancing Translational Sciences (UL1TR001105) of the National Institutes of Health. MS received support from a VA Health Services Research and Development Career Development Award (award 11-215). The content is solely the responsibility of the authors and does not necessarily represent the official views of the $\mathrm{NIH}$. The views expressed in this article are those of the authors and do not necessarily reflect the position or policy of the Department of Veterans Affairs or the US government.

Competing interests None declared.

Patient consent Not required.

Ethics approval Given that the meta-analysis only included data from previously published studies and individual patient-level data were not used, the study was considered exempt from institutional review board approval.

Provenance and peer review Not commissioned; externally peer reviewed.

Open access This is an open access article distributed in accordance with the Creative Commons Attribution Non Commercial (CC BY-NC 4.0) license, which permits others to distribute, remix, adapt, build upon this work non-commercially, and license their derivative works on different terms, provided the original work is properly cited, appropriate credit is given, any changes made indicated, and the use is non-commercial. See: http://creativecommons.org/licenses/by-nc/4.0/

\section{REFERENCES}

1. Benjamin EJ, Virani SS, Callaway CW, et al. Heart disease and stroke statistics-2018 update: a report from the American Heart Association. Circulation 2018;137:e67-e492.

2. Chan PS, McNally B, Tang F, et al. Recent trends in survival from out-of-hospital cardiac arrest in the United States. Circulation 2014;130:1876-82.

3. Spaulding CM, Joly LM, Rosenberg A, et al. Immediate coronary angiography in survivors of out-of-hospital cardiac arrest. $N$ Engl J Med 1997;336:1629-33.

4. O'Gara PT, Kushner FG, Ascheim DD. 2013 ACCF/AHA guideline for the management of ST-elevation myocardial infarction: executive summary: a report of the American college of cardiology foundation/ American heart association task force on practice guidelines: developed in collaboration with the American college of emergency physicians and society for cardiovascular angiography and interventions. Catheter Cardiovasc Interv 20132013;82:E1-27.

5. Mooney MR, Unger BT, Boland LL, et al. Therapeutic hypothermia after out-of-hospital cardiac arrest: evaluation of a regional system to increase access to cooling. Circulation 2011;124:206-14.

6. Vyas A, Chan PS, Cram P, et al. Early coronary angiography and survival after out-of-hospital cardiac arrest. Circ Cardiovasc Interv 2015;8:e002321.

7. Callaway CW, Schmicker RH, Brown SP, et al. Early coronary angiography and induced hypothermia are associated with survival and functional recovery after out-of-hospital cardiac arrest. Resuscitation 2014;85:657-63.

8. Camuglia AC, Randhawa VK, Lavi S, et al. Cardiac catheterization is associated with superior outcomes for survivors of out of hospital cardiac arrest: review and meta-analysis. Resuscitation 2014;85:1533-40.

9. Larsen JM, Ravkilde J. Acute coronary angiography in patients resuscitated from out-of-hospital cardiac arrest--a systematic review and meta-analysis. Resuscitation 2012;83:1427-33.

10. Merchant RM, Abella BS, Khan M, et al. Cardiac catheterization is underutilized after in-hospital cardiac arrest. Resuscitation 2008;79:398-403.
11. Moher D, Liberati A, Tetzlaff J, et al. Preferred reporting items for systematic reviews and meta-analyses: the PRISMA statement. BMJ 2009;339:b2535.

12. Stroup DF, Berlin JA, Morton SC, et al. Meta-analysis of observational studies in epidemiology: a proposal for reporting. Meta-analysis Of Observational Studies in Epidemiology (MOOSE) group. JAMA 2000;283:2008-12.

13. Wells GA, Shea B, O'Connell D, et al, 2018. The Newcastle-Ottawa Scale (NOS) for assessing the quality of nonrandomised studies in meta-analyses. Available from: http://www.ohri.ca/programs/clinical_ epidemiology/oxford.asp [accessed 21 Apr 2015].

14. DerSimonian R, Laird N. Meta-analysis in clinical trials. Control Clin Trials 1986;7:177-88.

15. Woolf B. On estimating the relation between blood group and disease. Ann Hum Genet 1955;19:251-3.

16. Aurore $A$, Jabre $P$, Liot $P$, et al. Predictive factors for positive coronary angiography in out-of-hospital cardiac arrest patients. Eur $J$ Emerg Med 2011;18:73-6.

17. Bro-Jeppesen J, Kjaergaard J, Wanscher M, et al. Emergency coronary angiography in comatose cardiac arrest patients: do real-life experiences support the guidelines? Eur Heart J Acute Cardiovasc Care 2012;1:291-301.

18. Dankiewicz J, Nielsen N, Annborn M, et al. Survival in patients without acute ST elevation after cardiac arrest and association with early coronary angiography: a post hoc analysis from the TTM trial. Intensive Care Med 2015;41:856-64.

19. Geri G, Dumas F, Bougouin W, et al. Immediate Percutaneous Coronary Intervention Is Associated With Improved Short- and LongTerm Survival After Out-of-Hospital Cardiac Arrest. Circ Cardiovasc Interv 2015;8:e002303.

20. Hollenbeck RD, McPherson JA, Mooney MR, et al. Early cardiac catheterization is associated with improved survival in comatose survivors of cardiac arrest without STEMI. Resuscitation 2014;85:88-95

21. Kleissner M, Sramko M, Kohoutek J, et al. Impact of urgent coronary angiography on mid-term clinical outcome of comatose out-ofhospital cardiac arrest survivors presenting without ST-segment elevation. Resuscitation 2015;94:61-6.

22. Nanjayya VB, Nayyar V. Immediate coronary angiogram in comatose survivors of out-of-hospital cardiac arrest--an Australian study. Resuscitation 2012;83:699-704.

23. Nielsen N, Hovdenes J, Nilsson F, et al. Outcome, timing and adverse events in therapeutic hypothermia after out-of-hospital cardiac arrest. Acta Anaesthesiol Scand 2009;53:926-34.

24. Strote JA, Maynard C, Olsufka M, et al. Comparison of role of early (less than six hours) to later (more than six hours) or no cardiac catheterization after resuscitation from out-of-hospital cardiac arrest. Am J Cardiol 2012;109:451-4.

25. Tømte O, Andersen G $\varnothing$, Jacobsen D, et al. Strong and weak aspects of an established post-resuscitation treatment protocol-a five-year observational study. Resuscitation 2011;82:1186-93.

26. Weiser C, Testori C, Sterz F, et al. The effect of percutaneous coronary intervention in patients suffering from ST-segment elevation myocardial infarction complicated by out-of-hospital cardiac arrest on 30 days survival. Resuscitation 2013;84:602-8.

27. Zanuttini D, Armellini I, Nucifora G, et al. Impact of emergency coronary angiography on in-hospital outcome of unconscious survivors after out-of-hospital cardiac arrest. Am J Cardiol 2012;110:1723-8.

28. Casella G, Carinci V, Cavallo P, et al. Combining therapeutic hypothermia and emergent coronary angiography in out-of-hospital cardiac arrest survivors: Optimal post-arrest care for the best patient. Eur Heart J Acute Cardiovasc Care 2015;4:579-88.

29. Bougouin W, Lamhaut L, Marijon E, et al. Characteristics and prognosis of sudden cardiac death in Greater Paris: populationbased approach from the Paris Sudden Death Expertise Center (Paris-SDEC). Intensive Care Med 2014;40:846-54.

30. Noc M, Fajadet J, Lassen JF, et al. Invasive coronary treatment strategies for out-of-hospital cardiac arrest: a consensus statement from the European association for percutaneous cardiovascular interventions (EAPCI)/stent for life (SFL) groups. Eurolntervention 2014;10:31-7. 